\title{
Royal Society puts personalized medicine in perspective
}

Pharmacogenetics tests are still over a decade away from living up to their promise.

\section{Malorye Allison Branca}

Personalized medicine is a more distant goal than the public has been led to believe, and there are still mammoth obstacles ahead, according to a recent report from the UK's prestigious Royal Society. The report, entitled Personalised medicines: hopes and realities, removes the hype surrounding pharmacogenetics-based testing by stating that an era in which patients are prescribed treatments based on their genetic make-up will not be with us for at least another 15-20 years.

Pharmaceutical industry representatives are hailing the report as timely, mostly positive and providing an appropriate perspective on the area. "It reflects what I keep preaching: modesty, realism, but robust optimism," says Klaus Lindpaintner, head of Roche Genetics and the Roche Center for Medical Genomics.

Although the report has not received much public attention, "It's putting a flag up, saying this is an important area to watch, and that's good," says Karol Sikora, Professor of Cancer Medicine at London's Imperial College.

Sir David Weatherall, chair of the working group that produced the Society's report, agrees, saying the field is worthy of attention now because it holds so much promise. Breaking common diseases down into subtypes could "improve therapy while saving time and wasted money," says Weatherall, Emeritus Regius Professor of Medicine and the retired founding director of the Weatherall Institute of Molecular Medicine at Oxford.

The report states that developments are likely to occur in cancer first, and that in general there will be a gradual rather than a revolutionary movement towards the development and use of pharmacogenomics-based tests.

Companies are increasing efforts to obtain DNA samples from trial populations on drugs in development. The report says that pharmacogenomicsbased analysis of samples occurs in around $20-30 \%$ of current early-stage programmes. In the next 5 years, up to $10 \%$ of late-stage research will test a therapy with an associated diagnostic.
Although pharmaceutical companies are already looking at personalized applications for some candidate drugs in the pipelines, it is not clear who will study the drugs already on the market. (For example, more than half the drugs on the market in the UK are generics.) Companies have no obvious motive to shrink an established drug's market by launching a test that could determine probable 'responders' from 'non-responders'. Government organizations and charities, meanwhile, will find it difficult to finance these studies, and the report suggests that public-private partnerships could perhaps help to address this financial burden.

\section{"The big question is who will pay to move the field into mainstream clinical practice."}

New technologies - such as geneexpression arrays - that will make gene studies faster, cheaper and easier are moving through to the clinic, but the big question is who will pay to move the field into mainstream clinical practice. For example, few, if any, cost-effectiveness studies have been carried out yet. In some cases, oldfashioned methods such as trial-and-error

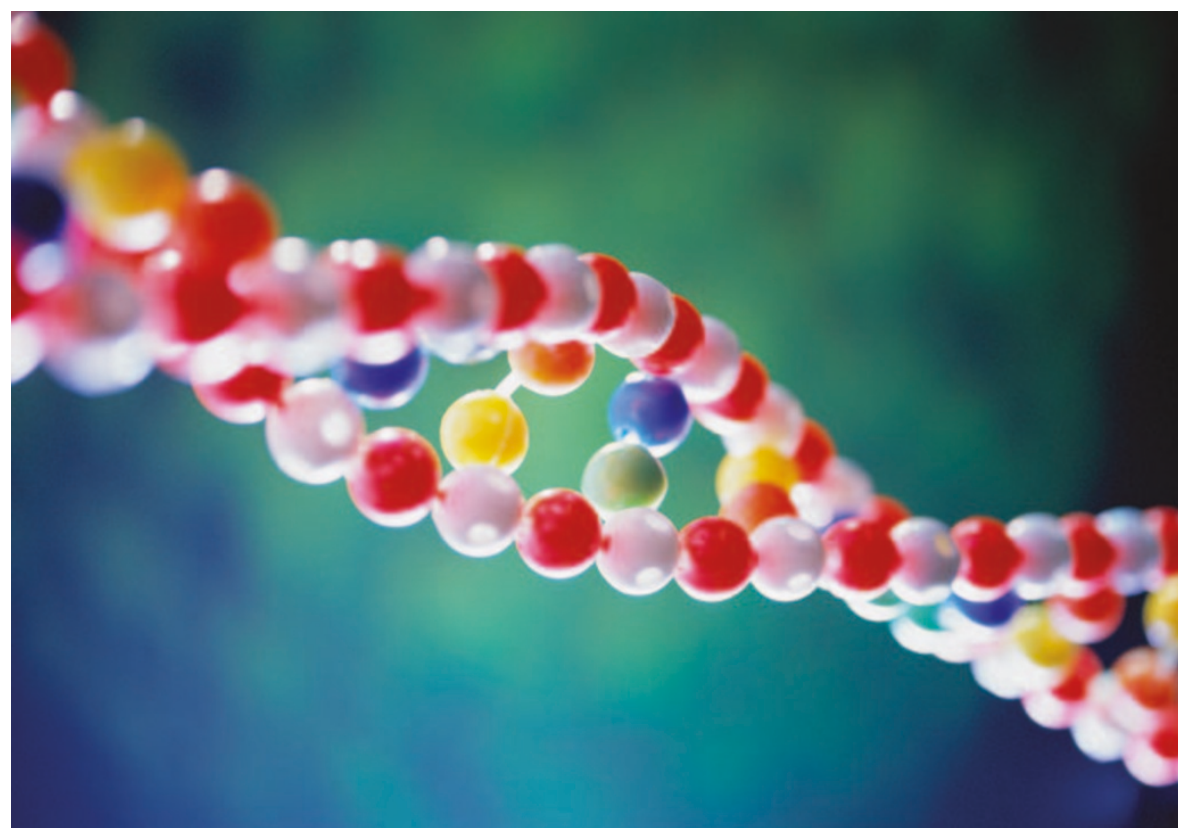

Companies are increasing efforts to obtain DNA samples from trial populations. prescribing might end up being cheaper than sophisticated new tests.

Figuring out how to best fit these new tools and procedures into clinical practice is a big challenge. A full understanding of the value of tests will require a huge input from healthcare providers. "Whether it is the doctors or the community nurses who will be doing the testing, it would require a major education campaign," Weatherall says.

Richard Ley, a spokesman for the Association of the British Pharmaceutical Industry (ABPI), doesn't agree with everything in the report, but he hopes that it will help correct common misperceptions about personalized medicine. "At least it was not created with any specific agenda," says Ley. Such "thoughtful and considered" studies, he adds, will be helpful to governments and agencies in charge of formulating policy. 